\title{
ANÁLISE DO VESTUÁRIO ESPORTIVO FEMININO SOB A ÓTICA DO PÚBLICO PLUS SIZE: ESTUDO SOBRE ASPECTOS ERGONÔMICOS
}

\section{ANAL YSIS OF FEMALE SPORTS CLOTHING FROM UNDER THE OPTICS THE PUBLIC PLUS SIZE: STUDY ON ERGONOMIC ASPECTS}

\author{
Daiane de Lourdes Toledo ${ }^{1}$, M.Sc. \\ daiatol@gmail.com e https://orcid.org/0000-0003-3520-716X \\ Giselle Schmidt Alves Diaz Merino², D.Sc. \\ gisellemerino@gmail.com e https://orcid.org/0000-0003-4085-3561 \\ Eugênio Andrés Dias Merino ${ }^{2}$, D.Sc. \\ eugenio.merino@ufsc.br e https://orcid.org/0000-0002-7113-6031 \\ Ricardo Triska ${ }^{1}$, D.Sc. \\ ricardo.triska@ufsc.br e https://orcid.org/0000-0002-7113-6031
}

\footnotetext{
${ }^{1}$ PósDesign, Universidade Federal de Santa Catarina - UFSC, Florianópolis, Santa Catarina, Brasil

${ }^{2}$ Núcleo de Gestão de Design - NGD, PósDesign e PPGEP, Universidade Federal de Santa Catarina - UFSC, Florianópolis, Santa Catarina, Brasil
}

moda plus size, ergonomia, vestuário esportivo

Os índices de obesidade no Brasil estão aumentando e trazendo diversas implicações para o cotidiano das pessoas. Também há, entretanto, um crescente interesse sobre saúde, bons hábitos alimentares e práticas esportivas. O presente estudo buscou compreender como é a experiência das usuárias plus size com relação ao vestuário esportivo. A pesquisa foi dividida em três etapas, sendo a primeira de levantamento teórico, a segunda aplicada, por meio de entrevistas, e a terceira de redação final. No total, foram 34 participantes, todas do sexo feminino, escolhidas por fazerem parte de um grupo de emagrecimento na cidade de Caçador/SC, o programa "EmagreSer". Como resultado da avaliação das peças do vestuário, constatou-se que houve pouca diferença na satisfação por parte do público de IMC normal com relação ao público plus size, sendo constatados diversos pontos de melhoria no geral, tais como: adequação de materiais para maior conforto térmico e hídrico, ajuste da grade de tamanhos para modelagem mais adequada, melhoria da confecção para evitar o desgaste das costuras e, dentre outros, a disponibilização de peças de qualidade com preços acessíveis.

plus size fashion, ergonomics, sportswear

The obesity rates in Brazil are advancing and bringing implications to people's daily lives. However, there is also a growing interest in health, good eating habits and sports. The present study sought to understand how the experience of plus size users is in relation to sports clothing. The research was divided into three stages, the first being a theoretical survey, the second applied through interviews, and the third of final writing. In total, 34 participants, all female, weight loss group in the city of Caçador - SC, the "EmagreSer" program. As a result of the evaluation of the garments, it was found that there was little difference in satisfaction on the part of the normal BMI audience in relation to the plus size audience, with several points of improvement in general, such as: adaptation of materials for greater thermal comfort and hidric, adjustment of sizes for more adequate modeling, improvement the confection to avoid wearing out the seams and, among others, and making quality parts available at low prices. 


\section{Introdução}

A obesidade é uma doença que se caracteriza pelo excesso de gordura corporal, comprometendo a saúde dos indivíduos e podendo causar alterações metabólicas, dificuldades respiratórias e de locomoção (WANDERLEY; FERREIRA, 2010). Pode, ainda, ser um fator de risco para outras doenças, como diabetes melittus tipo II, doenças cardiovasculares e alguns tipos de câncer (WANDERLEY; FERREIRA, 2010).

Nos últimos dez anos, o índice de obesidade da população brasileira aumentou significativamente. Considerando os indivíduos acima de 18 anos e residentes nas capitais, o percentual passou de $12 \%$, em 2006, para 19\% em 2016, um crescimento de 60\% durante o período (SOUZA et al., 2019). Segundo a Organização Mundial de Saúde (OMS), a projeção para 2015 foi de 2,3 bilhões de pessoas acima do peso e de 700 milhões de pessoas obesas. Os índices com maior crescimento foram os de países em desenvolvimento, como o Brasil (TAVARES; NUNES; SANTOS, 2010).

O Vigitel, que compõe o sistema de Vigilância de Fatores de Risco para doenças crônicas não transmissíveis (DCNT) do Ministério da Saúde (2018), registrou crescimento no excesso de peso da população brasileira, na qual 55,7\% das pessoas estão acima do peso. Comparando com os índices de 2006, houve um aumento de $30,8 \%$ nesta taxa e a faixa etária mais acometida foi entre 18 e 24 anos. Mulheres apresentaram $40 \%$ de aumento de peso, enquanto homens $21,7 \%$ (SAÚDE, 2019).

Alguns estudos, como o de Fonseca-Junior (2013), apontam que a prática de exercícios físicos periódicos por obesos, prescritas de acordo com cada indivíduo, suas restrições e necessidades, são favoráveis à redução dos riscos de morbidade e mortalidade, mesmo que em um primeiro momento não promova o emagrecimento, mas repercutindo na melhora dos indicadores de saúde. (FONSECA-JUNIOR, 2013).

A prática de atividades físicas, além de promover a saúde física, também proporciona bem-estar e por isso, gradativamente, está sendo inserida na rotina de vida das pessoas, com sua importância reconhecida (LIMA E MAFFIA, 2010). Contudo mulheres adultas ainda encontram algumas dificuldades para conciliar a rotina de atividades físicas com a família e o trabalho, sendo elas as que detém a maior sensibilidade com relação ao assunto, por se preocuparem mais com questões de saúde e estética (LIMA E MAFFIA, 2010).

A busca pela saúde e bem-estar, pela prática esportiva e pela melhora dos hábitos alimentares estão em crescimento. De 2008 a 2018 o consumo de frutas e hortaliças aumentou em 15,5\%, ao passo que de 2009 a 2018 a prática de atividades físicas aumentou em 25,7\% (SAÚDE, 2019). Entretanto ainda há prevalência de obesidade na população, principalmente nos grupos atendidos pelo Sistema Único de Saúde (SUS), se comparado à população em geral. Mais de $60 \%$ das mulheres que frequentam o Sistema Único de Saúde (SUS) apresentam algum grau de sobrepeso e/ou obesidade (ROSA et al., 2011).

A promoção da saúde pela prática de atividades físicas carece de alguns elementos. Além dos acessórios específicos para cada modalidade, geralmente disponibilizados pelas academias, o vestuário adequado é um dos principais artefatos necessários para a prática esportiva plena, pois sua adequação ao corpo dos usuários pode contribuir de diversas formas para seu desempenho, tais como: segurança, conforto, delineamento corporal e até mesmo para a motivação e satisfação com a atividade (NASCIMENTO, 2014).

Unindo os contextos de aumento dos índices de obesidade no Brasil, com maior prevalência em mulheres, e o aumento da busca por atividades físicas da população em geral, considerando que o vestuário contribui para a adesão das usuárias nos esportes, o presente estudo busca compreender como é a experiência das usuárias do vestuário esportivo plus size.

Para Gomes Filho (2006, p. 72), os atributos e características ergonômicas dos produtos variam de acordo com o perfil corporal e volumétrico de cada indivíduo, de modo que tal variação influencia "decisivamente a 
qualidade desejada ou esperada do manejo" ao se realizar uma atividade qualquer. Logo, quanto maior a adequação do produto ao usuário, maior é a chance de sucesso de sua atividade (NASCIMENTO, 2014).

Santos (2016), salienta que o público feminino com sobrepeso ou obeso não está representado na indústria da moda, embora seja um público com grande potencial de mercado. Assim, a relevância deste estudo está apoiada na ampliação dos conhecimentos sobre as perspectivas do público feminino plus size com relação ao vestuário esportivo, considerando que no design a compreensão do universo dos usuários é uma prática necessária, já que sua definição está norteada por um "processo de resolução de problemas centrado no usuário" (BEST, 2012, p. 40).

Para visualizar o cenário atual de pesquisa da temática, foi feito um levantamento em bases de dados com as chaves de busca "fashion" AND "plus size", a qual encontrou o maior resultado na base Scopus, com 38 publicações. Dessas, o relatório bibliométrico realizado pelo software RStúdio apontou que apenas 32 são artigos, cujas áreas principais são: saúde, nutrição e moda. O período destas publicações varia entre 1998 e 2019, sendo esse o ano com maior produção até o momento, com 07 (sete) documentos - de acordo com a amostra verificada em março de 2020. Dos artigos localizadas, foram selecionados os 03 (três) mais relevantes para comporem a fundamentação teórica deste estudo.

\section{Fundamentação Teórica}

Neste tópico são apresentados os resultados da pesquisa bibliográfica referente aos temas essenciais para o artigo: Ergonomia do Vestuário e Design Centrado no Usuário; Sistema de Moda e Vestuário Plus Size.

\subsection{Design Centrado no Usuário e Vestuário Ergonômico}

A ergonomia surgiu com enfoque na área laboral, como um estudo da interação homem-objeto, com foco na melhoria destas interações, e há muito tempo os estudos ergonômicos transcenderam essa abordagem. Pelo seu caráter multidisciplinar, a ergonomia é aplicada em diversas áreas, incluindo o Design, onde contribui para o aprimoramento de produtos e serviços no que tange à sua relação com o uso humano (GOMES FILHO, 2010; IIDA, 2005).

Sob a ótica da ergonomia, os produtos são "meios para que o homem possa executar determinadas funções. Esses produtos, então, passam a fazer parte de sistemas homem-máquina-ambiente" (IIDA, 2005, p. 313). Dentre as características básicas dos produtos ergonômicos destacam-se a qualidade técnica, que aborda a funcionalidade, a qualidade ergonômica, que compreende a relação entre o produto e o usuário - incluindo adequação antropométrica e manuseio -, e, por fim, a qualidade estética, que representa as características visuais atrativas dos produtos (IIDA, 2005). Em Iida (2016, p. 264), o autor atualiza o conceito das características desejáveis dos produtos, resumindo-as em três: qualidade técnica - relacionada ao bom funcionamento do produto -, usabilidade e agradabilidade. Essas últimas são pertencentes aos aspectos ergonômicos do produto, aquela relacionada à facilidade de uso e experiência física, enquanto que essa está relacionada aos aspectos emocionais do uso, como 'preferências, gostos pessoais e prazer no uso" (IIDA, 2016).

Com o aperfeiçoamento da técnica, os estudos ergonômicos desenvolveram-se com maior atenção ao usuário, passando a ter esse como ponto central do projeto desde a sua concepção. Ao fazer isso, minimizamse os problemas e humaniza-se o processo e os produtos (MERINO, 2014). Uma das técnicas utilizadas no design centrado no usuário é a abordagem empática, na qual há uma aproximação dos designers com o cotidiano dos usuários, visando maximizar a adequação do produto às necessidades do público (KOUPRIE; VISSER, 2009). Esse método permite que os designers sintam algumas restrições que seu público possui, de 
modo que o profissional consiga se envolver mais profundamente e, a partir dessa experiência e sem julgamentos, desenvolver projetos melhor adequados (KOUPRIE; VISSER, 2009).

Produtos de vestuário para funções específicas, como é o caso do vestuário esportivo, demandam mais atenção quanto à sua adequação ergonômica, pois são artefatos que dão suporte à execução de uma tarefa nesse caso à realização da atividade física -, demandando elasticidade, conforto térmico, manejo da transpiração e durabilidade (ROSA, 2011). Além disso, é necessário que os produtos tenham usabilidade, que para Iida (2016, p. 258) significa "eficiência, facilidade, comodidade e segurança no uso", o que inclui a "adequação antropométrica e biomecânica, compatibilidades de movimentos, [...] conforto e segurança", todos estes critérios precisam ser contemplados apesar das restrições e diferenças de cada público. $\mathrm{O}$ vestuário atua como uma extensão do corpo humano e pode implicar negativamente ou positivamente nas ações realizadas pelos usuários, influenciando na relação do sujeito com o ambiente (MONTEMEZZO, 2003).

\subsection{Vestuário Plus Size}

A demanda por vestuário plus size está em crescimento no Brasil e a indústria da moda vem se adaptando a este novo perfil, mas ainda priorizam a apresentação das coleções em modelos tradicionalmente magras (SANTOS; NICOLAU, 2012). Possivelmente, essa transição morosa ocorre por que na sociedade ocidental contemporânea ainda há uma grande valorização do corpo magro feminino, ao passo que culturalmente as pessoas obesas são vistas com preconceito, como resultado do comportamento inadequado dos indivíduos, muitas vezes gerando a segregação das pessoas obesas em grupos, prejuízo em entrevistas de emprego e outros malefícios nos mais diversos meios (LIMATIUS, 2019).

Para Freitas et al. (2010), as mulheres têm uma percepção da sua imagem corporal menos positiva que o público masculino e justificam que a causa é o fato de estarem acima do peso, prejudicando sua autoestima. Dentro do universo da moda, os preconceitos com relação à obesidade feminina são ainda maiores e embora já surjam mudanças em propagandas e perfis de grifes, ainda há o predomínio do corpo magro feminino como padrão ideal (LIMATIUS, 2019).

Outra razão para o preterimento do público obeso pode ser a complexidade técnica na confecção de vestuário plus size (BETTI, 2014). A ampliação de uma peça tamanho 42 para o 52 precisa de uma remodelação completa e não apenas a ampliação proporcional, demandando aumento do investimento e especialização dos profissionais, tornando-se um desafio para as indústrias trabalharem com este novo padrão de corpo (BETTI, 2014). Além disso, quando se trata de tabela de medidas femininas padronizada, no Brasil ainda não há uma normatização a ser seguida pelas empresas, ocasionando diferenças de tamanho até em peças de uma mesma numeração (ABNT/CB-17, 2014).

Algumas mudanças neste padrão estão sendo observadas, capitaneadas pela influência dos blogs de moda plus size, esses que atuam em prol do empoderamento desse público, uma vez que, em sua maioria, são gerenciados por blogueiras plus size que expõem com liberdade sua opinião e várias opções de produção de moda, à margem da indústria padrão (LIMATIUS, 2019). Desse modo há uma força sobre o mercado no que se refere a esse novo perfil de consumidores, em uma constante em que a moda influencia o corpo e o corpo influencia a moda (SILVA, 2012).

Outros desafios no desenvolvimento de vestuário plus size na atualidade são compostos por questões mais subjetivas, como a necessidade de conhecer profundamente o público, ter uma abordagem empática que vá além do conhecimento superficial de suas necessidades, que enxergue suas dores e limitações cotidianas (KOUPRIE; VISSER, 2009). É necessário colocar o público no centro do projeto, por meio de metodologias de design centrado no usuário (MERINO, 2014); e, como comentam Schulte (2015) e Moorhouse e Moorhouse (2017), ainda, construir o projeto com respeito e ética ao meio ambiente e à sociedade. 
O respeito ao meio ambiente surge em razão do clico tradicional da moda, dividido em etapas que vão desde o lançamento de uma coleção até o fim do interesse do público na mesma. Este ciclo ocorre para todos os produtos novos e funciona como uma engrenagem, baseado no consumo constante e efêmero (SCHULTE, 2015). Por isso ao falar sobre a moda é indispensável abordar seus impactos socioambientais negativos, de modo que quaisquer soluções no âmbito do produto precisam estar alinhadas com a sustentabilidade, sendo fundamental "ter um foco socioambiental e ético no design para garantir que os produtos sejam, na medida do possível, de baixo impacto para o meio ambiente" (SCHULTE, 2015, p. 71).

Unindo a abordagem da sustentabilidade com o design de vestuário esportivo, Kozlowski; Bardecki e Searcy (2019, p. 13) sintetizaram dentro da categoria de ferramentas do design participativo um grupo que intitularam como ferramentas de co-design, isto é, abordagens empáticas onde os designers se aproximam efetivamente dos usuários e aprimoram proficuamente o produto para cada perfil, dentro de cada especificidade reconhecida, garantindo a melhor experiência e promovendo o que denominaram como "durabilidade emocional". Esse conceito permite inferir que haverá uma redução dos impactos ambientais a partir da produção de peças com longa durabilidade que superem as expectativas e satisfaçam realmente o público, acarretando no aumento da periodicidade de consumo, reduzindo, por consequência, o consumo insustentável de recursos (KOZLOWSKI; BARDECKI E SEARCY, 2019).

\section{Procedimentos Metodológicos}

A presente pesquisa tem abordagem qualitativa e natureza aplicada, pois "objetiva gerar conhecimentos para aplicação prática dirigidos à solução de problemas específicos" (PRODANOV; FREITAS, 2013, p. 51), e foi organizada em três etapas: a primeira foi de levantamento teórico, a fim de ampliar a compreensão sobre o tema e construir a base teórica de sustentação das etapas seguintes, com levantamento realizado no portal de periódicos CAPES, no Banco de Teses e Dissertações e em livros. A segunda etapa consistiu na coleta de dados por meio de entrevistas com o público feminino participante de um programa de emagrecimento saudável no município de Caçador-SC. Por fim, a terceira etapa foi de análise dos dados coletados e redação final da pesquisa.

A coleta de dados foi realizada por meio de entrevistas presenciais ou virtuais com roteiro semiestruturado, tendo um total de 10 (dez) perguntas e elaborado a fim de coletar dados sociodemográficos, índice de massa corporal (IMC) das participantes, modalidades e frequência de práticas esportivas, tamanho de manequim, tipos de vestuário esportivo utilizado e critérios de priorização na hora da compra do vestuário esportivo. Além disso, foi disponibilizada uma pergunta de resposta aberta, a qual permitiu a contribuição livre das participantes sobre a principal melhoria desejada quanto ao vestuário esportivo. Com isso, objetivou-se mensurar a percepção das entrevistadas sobre a utilização de vestuário esportivo de forma global.

Como critério de inclusão para a pesquisa considerou-se: ser participante assídua do programa de emagrecimento "EmagreSer"; ter mais que 18 anos e preferencialmente estar praticando atividade física. Os critérios de exclusão foram: não ser participante do referido programa de emagrecimento e idade inferior a 18 anos. Por critérios éticos, não foram coletadas informações referentes à identificação pessoal das participantes e nem coletadas imagens. Todas as participantes estavam de acordo com o Termo de Consentimento Livre Esclarecido - TCLE que lhes foi apresentado no início das entrevistas.

\section{Resultados e Discussões}

A amostra da pesquisa contou com a participação de 34 mulheres, todas frequentadoras do programa de emagrecimento "EmagreSer", programa ofertado no município de Caçador-SC. Para a entrevista, foi desenvolvido roteiro semiestruturado com 10 (dez) perguntas e aplicado com as 34 participantes para verificar a percepção delas sobre o vestuário esportivo que utilizam. A razão da escolha deste grupo deu-se 
pelas características que as 34 mulheres apresentam quanto à busca pelo emagrecimento saudável associada à prática esportiva, foco de interesse do presente estudo.

A coleta de dados foi realizada em visita à reunião do grupo de emagrecimento, onde presencialmente foi possível entrevistar 23 (vinte e três) mulheres, sendo as demais (onze) entrevistadas virtualmente com o auxílio de aplicativo, uma vez que não estavam presentes no dia da entrevista. A faixa etária das respondentes varia de 18 a 60 anos. A faixa etária com maior número de participantes é a de 26 a 30 anos, com 9 (nove) mulheres, 26,5\% do total, seguida das faixas etárias de 18 a 25 anos e de 41 a 50 anos, ambas com 7 (sete) participantes, 20,6\% cada, de 31 a 35 anos, com 6 (seis) respostas (17,6\%), de 36 a 40 anos, com 4 (quatro) respostas $(11,8 \%)$ e de 51 a 60 ano, com apenas uma participante $(2,9 \%)$.

A partir do peso e da altura das participantes foi calculado o Índice de Massa Corporal (IMC) das mesmas, estratificado da seguinte forma: 12 (doze) participantes possuem IMC até 24,9, considerado normal, 11 (onze) estão entre 25 e 29,9, que representa sobrepeso, 07 (sete) estão entre 30 e 34,9, considerada obesidade grau I e 04 (quatro) com índice de 35 a 39,9, representando a obesidade grau II. Optou-se por manter na pesquisa as participantes cujo IMC é considerado normal por se compreender que a participação deste grupo também é relevante para o estudo, inclusive como parâmetro comparativo.

Corroborando com a análise, Freitas et al. (2010, p. 397) desenvolveu uma pesquisa com 151 participantes (108 mulheres e 43 homens) sobre o padrão de beleza do corpo feminino, sendo utilizado como parâmetro o Índice de Massa Corporal (IMC). Os resultados apontaram que 88,4\% dos respondentes indicaram o corpo de menor IMC (magro) sendo o mais belo, enquanto $89,9 \%$ dos sujeitos consideraram o corpo que possuía o IMC mais alto (obeso) como o menos belo. Ainda, quando abordaram questões sobre a autopercepção e o nível de satisfação pessoal com a sua imagem corporal, $71,8 \%$ dos homens estavam satisfeitos, $15,4 \%$ indiferentes e 12,8\% insatisfeitos. Entres as mulheres, apenas 51,1\% estavam satisfeitas, $27,6 \%$ indiferentes e $21,3 \%$ insatisfeitas. Com o estudo, ressaltaram que a percepção da própria imagem corporal é mais positiva entre os homens do que entre as mulheres (FREITAS et al., 2010). A análise reforça a relevância da relação feminina com o próprio corpo e a insatisfação gerada - muitas vezes não declarada - pelo sobrepeso.

Também foi verificado o tamanho de roupa utilizado pelas participantes, o seu manequim. Dentre as respostas, 05 (cinco) participantes fazem uso de vestuário plus size, 13 (treze) utilizam vestuário tamanho G, 07 (sete) utilizam M e 09 (nove) utilizam tamanho P ou PP (quadro 1).

\begin{tabular}{|l|c|}
\hline IMC & Participantes \\
\hline IMC Normal & $\mathbf{1 2}$ \\
\hline G (entre os tamanhos 42 e 44) & 1 \\
\hline M (tamanho 40) & 7 \\
\hline P (entre os tamanhos 36 e 38) & 1 \\
\hline PP ou P (entre 34 e 36) & $\mathbf{7}$ \\
\hline Obesidade Grau I & 6 \\
\hline G (entre os tamanhos 42 e 44) & 1 \\
\hline Plus Size (acima do tamanho 46) & $\mathbf{4}$ \\
\hline Obesidade Grau II & 4 \\
\hline Plus Size (acima do tamanho 46) & $\mathbf{1 1}$ \\
\hline Sobrepeso & 6 \\
\hline G (entre os tamanhos 42 e 44) & 4 \\
\hline M (tamanho 40) & 1 \\
\hline P (entre os tamanhos 36 e 38) & $\mathbf{3 4}$ \\
\hline Total Geral & 3 \\
\hline
\end{tabular}

Quadro 1: Tamanho de manequim declarado pelas participantes. Fonte: elaborado pelos autores (2020). 
As respostas demonstraram variação na relação entre o IMC e o tamanho de manequim utilizado. Por exemplo: 01 (uma) participante, que está na categoria de sobrepeso, respondeu que utiliza o manequim "P", enquanto outras 04 (quatro), na mesma categoria, declararam usar " $\mathrm{M}$ " e 06 (seis) declararam utilizar o manequim "G". Esta questão pode ter relação com dois fatores: o primeiro motivado pela ausência de normatização para a tabela de medidas de vestuário feminino no Brasil, o que possibilita que cada empresa adote um parâmetro diferente (ABNT/CB-17, 2014), ou pode ser uma declaração diferente da realidade, tendo em vista que muitas mulheres não estão satisfeitas com excesso de peso (FREITAS et al., 2010).

Sobre a prática esportiva, 24 (vinte e quatro) praticam e 10 (dez) não praticam, apenas participam do programa de emagrecimento, conforme demonstra o Gráfico 1:

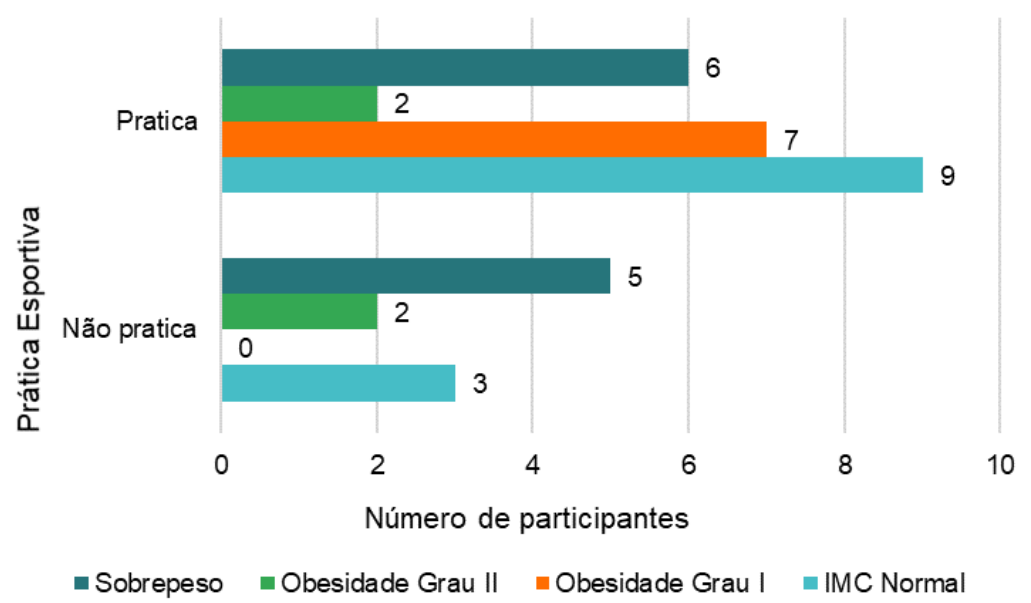

Gráfico 1: Praticantes de atividade física por perfil de IMC. Fonte: elaborado pelos autores (2020).

Pelo gráfico, percebe-se que há um engajamento maior com a prática esportiva por parte das participantes com o IMC na faixa de obesidade grau I, grupo no qual todas as 07 (sete) respondentes praticam atividades físicas, enfatizando a busca pelo ajuste de peso e saúde. Também há prevalência na prática esportiva no grupo composto pelas participantes com o IMC normal, onde 9 (nove) praticam e apenas 3 (três) não praticam. Nos grupos com IMC de sobrepeso e obesidade grau II os resultados foram semelhantes, já que no grupo com sobrepeso 6 (seis) respondentes praticam atividades físicas e 5 (cinco) não praticam, enquanto que no grupo obesidade grau II o número de praticantes é igual ao de não praticantes - 02 (dois) e 02 (dois).

As atividades físicas mencionadas foram: treino funcional, dança/zumba, pilates, ciclismo/bicicleta, academia/musculação, caminhada, corrida e vôlei. A distribuição geral de praticantes por modalidade está apresentada no Quadro 2. Ressalta-se que algumas respondentes praticam mais de uma modalidade, logo a distribuição foi feita pelo número de respostas.

\begin{tabular}{|c|c|c|c|c|c|}
\hline Modalidade & $\begin{array}{c}\text { IMC } \\
\text { Normal }\end{array}$ & Sobrepeso & $\begin{array}{c}\text { Obesidade } \\
\text { Grau I }\end{array}$ & $\begin{array}{c}\text { Obesidade } \\
\text { Grau II }\end{array}$ & $\begin{array}{c}\text { Total de } \\
\text { respostas }\end{array}$ \\
\hline Treino Funcional & 3 & 3 & 3 & 1 & 10 \\
\hline Dança/ Zumba & 2 & 2 & 1 & 1 & 6 \\
\hline Pilates & 1 & 2 & 2 & 0 & 5 \\
\hline Ciclismo/ bicicleta & 2 & 0 & 2 & 0 & 4 \\
\hline Academia/ Musculação & 2 & 2 & 0 & 0 & $\mathbf{4}$ \\
\hline Caminhada & 1 & 1 & 1 & 0 & $\mathbf{3}$ \\
\hline Corrida & 2 & 1 & 0 & 0 & $\mathbf{3}$ \\
\hline Vôlei & 0 & 0 & 1 & 0 & $\mathbf{1}$ \\
\hline
\end{tabular}

Quadro 2: Respostas sobre modalidades praticadas por perfil de IMC. Fonte: elaborado pelos autores (2020). 
No total 08 (oito) modalidades de atividades físicas foram citadas, o que confere uma certa diversidade ao estudo no que se refere à percepção do grupo com relação ao vestuário esportivo, haja vista os diferentes cenários. Sobre o tipo de vestuário utilizado para a prática esportiva, foram apresentadas as cinco opções mais comuns destas vestimentas: top, calça legging, bermuda justa, camiseta solta e macacão (Figura 1), havendo também a possibilidade de a participante relatar outro tipo de peça.

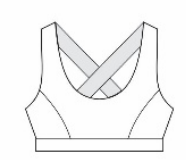

Top

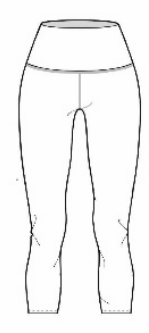

Calça Legging
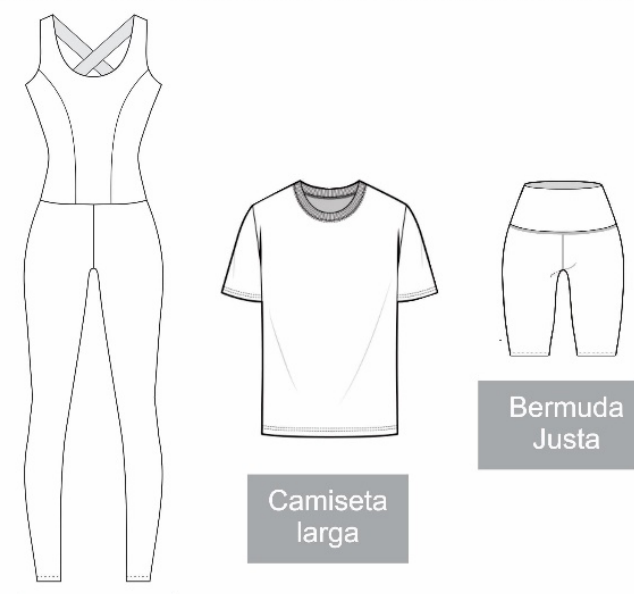

Bermuda Justa

Camiseta

larga

\section{Macacão}

Figura 1: Tipos de vestuário apresentados. Fonte: elaborada pelos autores.

Foram permitidos múltiplos apontamentos no que se refere ao tipo de vestuário utilizado, resultando em 72 respostas. Todas elas ficaram entre as peças de vestuário apresentadas, ou seja, não houve inclusões. As peças de vestuário mais utilizadas respectivamente foram: camiseta/blusa solta, com 26 respostas (76,4\% das 34 respondentes); calça legging, com 21 respostas $(61,7 \%)$; top feminine, 12 respostas $(35,2 \%)$; bermuda justa, 10 respostas, $(29,4 \%)$ e macacão, 3 respostas $(8,8 \%)$. A síntese das respostas por IMC é apresentada no Gráfico 2.

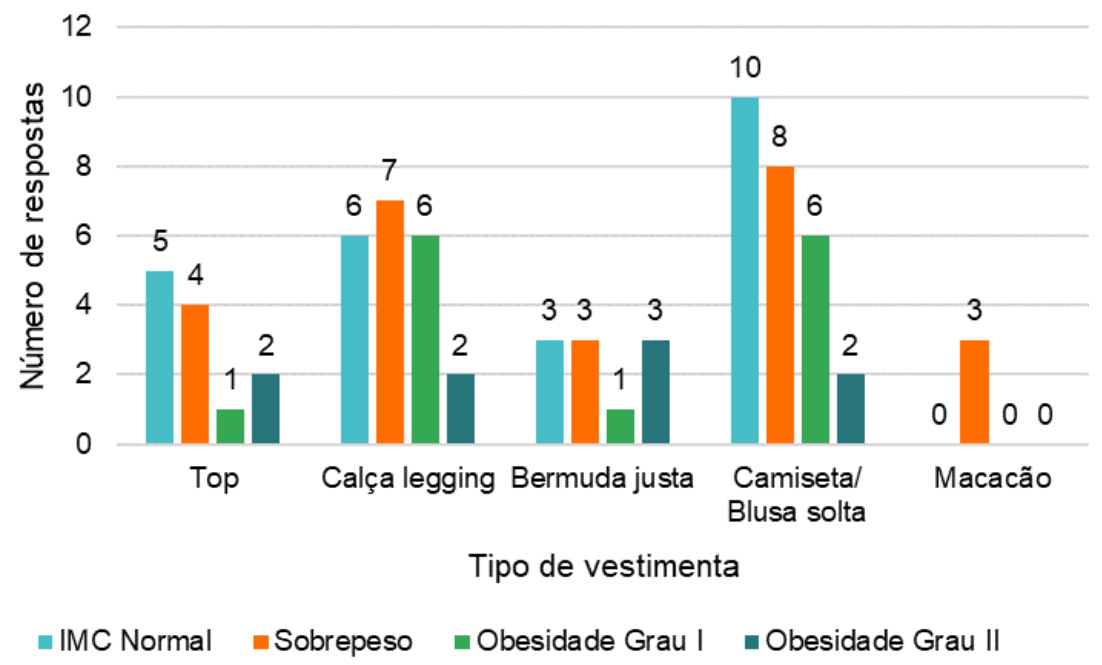

Gráfico 2: Tipo de vestuário utilizado por perfil de IMC das participantes (por respostas). Fonte: elaborado pelos autores (2020).

Não houve uma aparente preferência ou distinção por peças de vestuário entre o grupo de IMC normal se comparado com os demais grupos, ou seja, a escolha dos tipos de peça de vestuário esportivo é similar entre 
as participantes, independentemente do IMC. Com relação ao que as participantes priorizam na escolha do vestuário esportivo, foram apresentadas seis opções: conforto, durabilidade, estética e design, preço acessível, qualidade e, por fim, tecidos tecnológicos, havendo também a possibilidade de indicar outra resposta não listada. Foi permitido responder mais de um item por entrevistada, o que resultou em 62 apontamentos, sem inclusões. Essas opções foram disponibilizadas com base no conceito da "Adaptação Ergonômica de Produto" de Iida (2016), onde são listadas características desejáveis dos produtos, sendo elas "qualidade técnica, usabilidade e agradabilidade" (IIDA, 2016, p. 264).

Sobre as características desejáveis do vestuário esportivo, a que foi apontada como mais relevante para todas as respondentes foi o conforto $(48,4 \%)$, seguida pelo preço acessível $(14,5 \%)$ e qualidade $(14,5 \%)$. Na sequência foram citadas a durabilidade $(9,7 \%)$, estética e design $(8,1 \%)$ e, por fim, tecidos tecnológicos $(4,8 \%)$ - com o menor número de respostas.

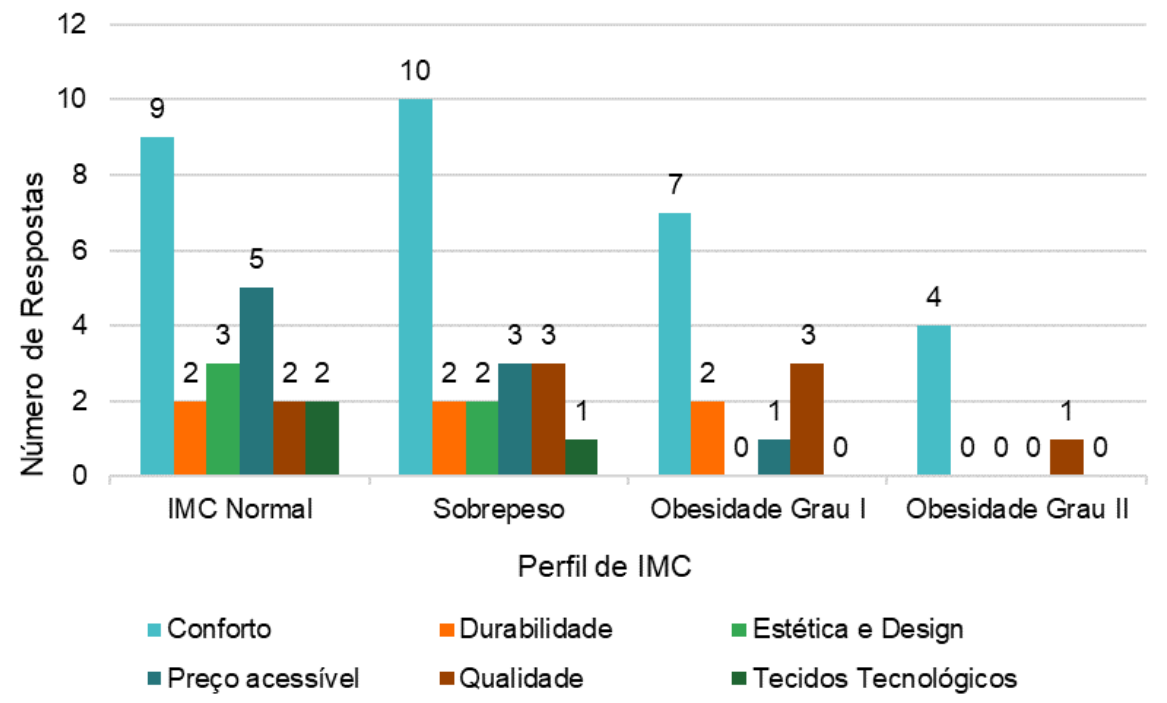

Gráfico 3: Características dos produtos priorizadas pelas participantes (por respostas). Fonte: elaborado pelos autores (2020).

O Gráfico 3 apresenta o número de repostas quanto às características desejáveis do vestuário com relação ao perfil de IMC das participantes. É possível identificar que conforme o IMC aumenta, as exigências quanto ao vestuário esportivo diminuem. Das 6 (seis) características apresentadas, apenas duas delas - conforto e qualidade - estão presentes nas respostas das participantes com perfil de IMC Obesidade Grau II, enquanto que as participantes com IMC compreendido nas faixas Normal e Sobrepeso indicaram, em alguma quantia, todas as características. Esse fato demonstra maior rigor nas escolhas por parte desses grupos, o que possivelmente é vivenciado em seu cotidiano, já que dispõem de maior amplitude de escolha dos produtos, diferentemente das participantes com o IMC na faixa da Obesidade Grau I e II, que têm menos opções de produtos disponíveis. À medida que o IMC aumenta, as participantes deixaram de citar "estética e design", "tecidos tecnológicos" e deram pouca atenção para "preço" e "durabilidade", enfatizando a sua necessidade principal de "conforto", respondido por todas as participantes com IMC de Obesidade Grau I e II.

A avaliação específica dos produtos foi realizada pelas próprias usuárias, considerando os itens que utilizam para a prática esportiva: top, calça legging, bermuda justa, camiseta/blusa solta e macacão. A síntese das respostas por perfil de IMC está nas Figuras 2 a 6, sendo apresentado no texto a síntese das respostas do grande grupo. 


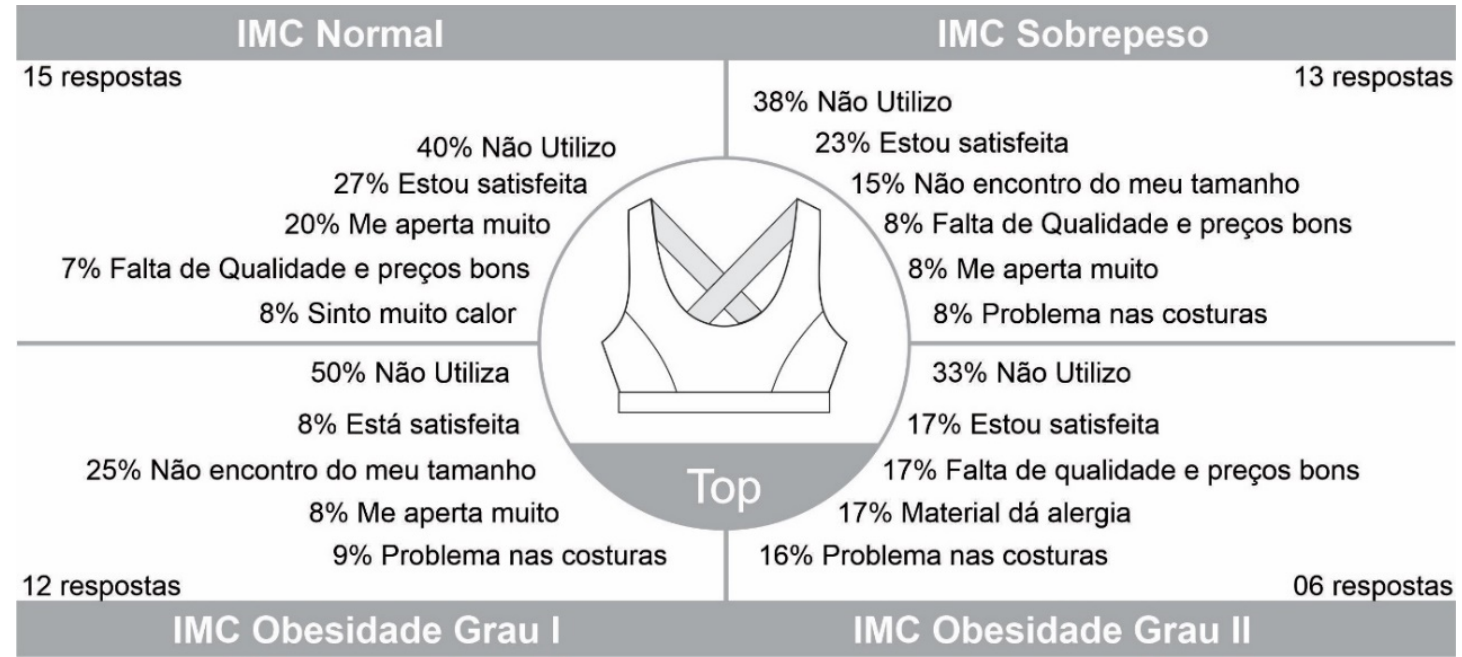

Figura 2: Avaliação do top pelas participantes. Fonte: elaborado pelos autores (2020).

O primeiro item avaliado foi o top (Figura 2). Considerando apenas as respostas sobre os principais problemas levantados pelo grande grupo, foram listados: as peças são muito apertadas ( 5 respostas), não encontra do seu tamanho ( 5 respostas), apresentam problema nas costuras ( 3 respostas), faltam no mercado produtos com qualidade e preços bons (3 respostas), o material causa alergia (1 resposta), muito calor na utilização (1 resposta).

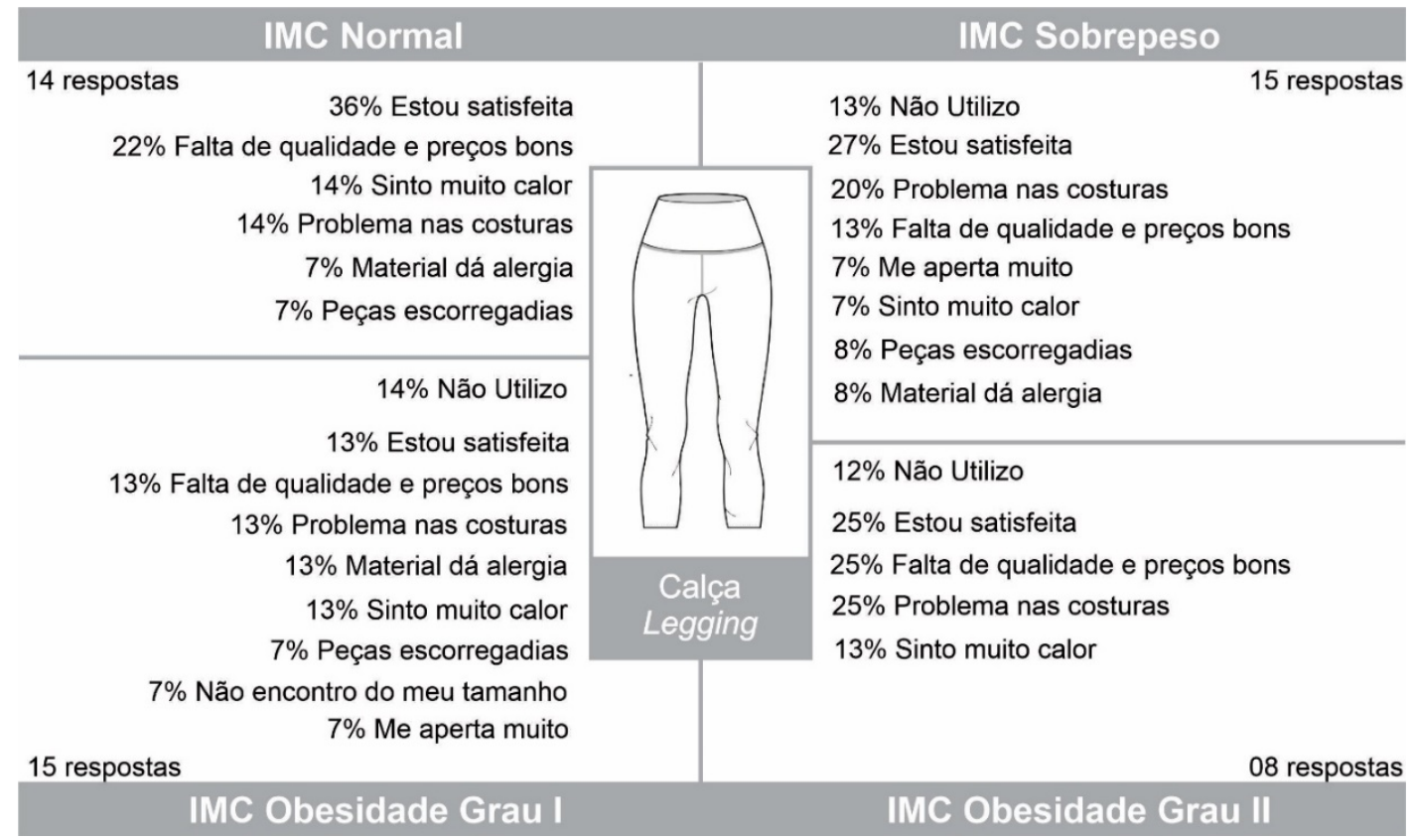

Figura 3: Avaliação da calça legging pelas participantes. Fonte: elaborado pelos autores (2020).

O segundo item avaliado foi a calça legging (Figura 3). Os principais problemas levantados pelo grande grupo foram: faltam no mercado produtos com qualidade e preços bons ( 9 respostas), apresentam problema nas costuras ( 9 respostas), muito calor na utilização (6 respostas), as peças são escorregadias (3 respostas), o material causa alergia (3 respostas), não encontra do seu tamanho (1 resposta). 


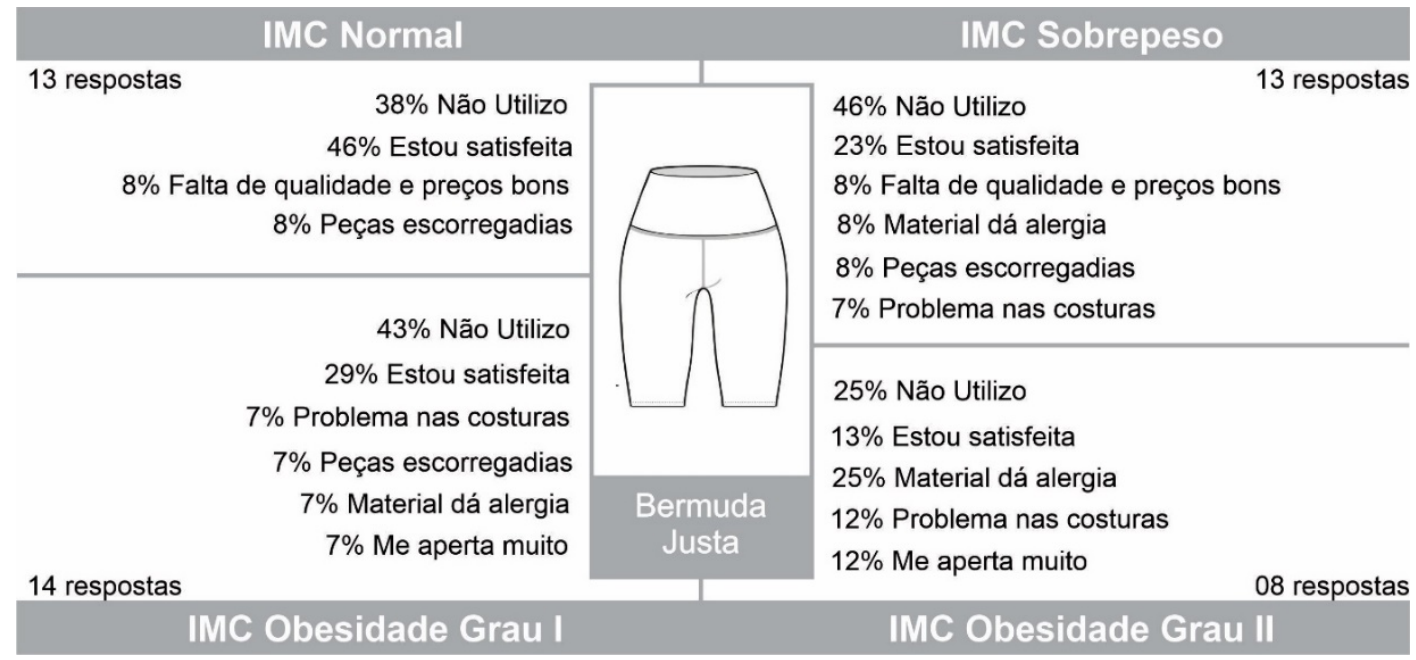

Figura 4: Avaliação da bermuda justa pelas participantes. Fonte: elaborado pelos autores (2020).

O terceiro item avaliado foi a bermuda justa (Figura 4). Os principais problemas levantados pelo grande grupo foram: o material causa alergia (4 respostas), as peças são escorregadias (3 respostas), apresentam problema nas costuras (3 respostas), as peças são muito apertadas ( 2 respostas), faltam no mercado produtos com qualidade e preços bons ( 2 respostas), não encontra do seu tamanho (1 resposta).

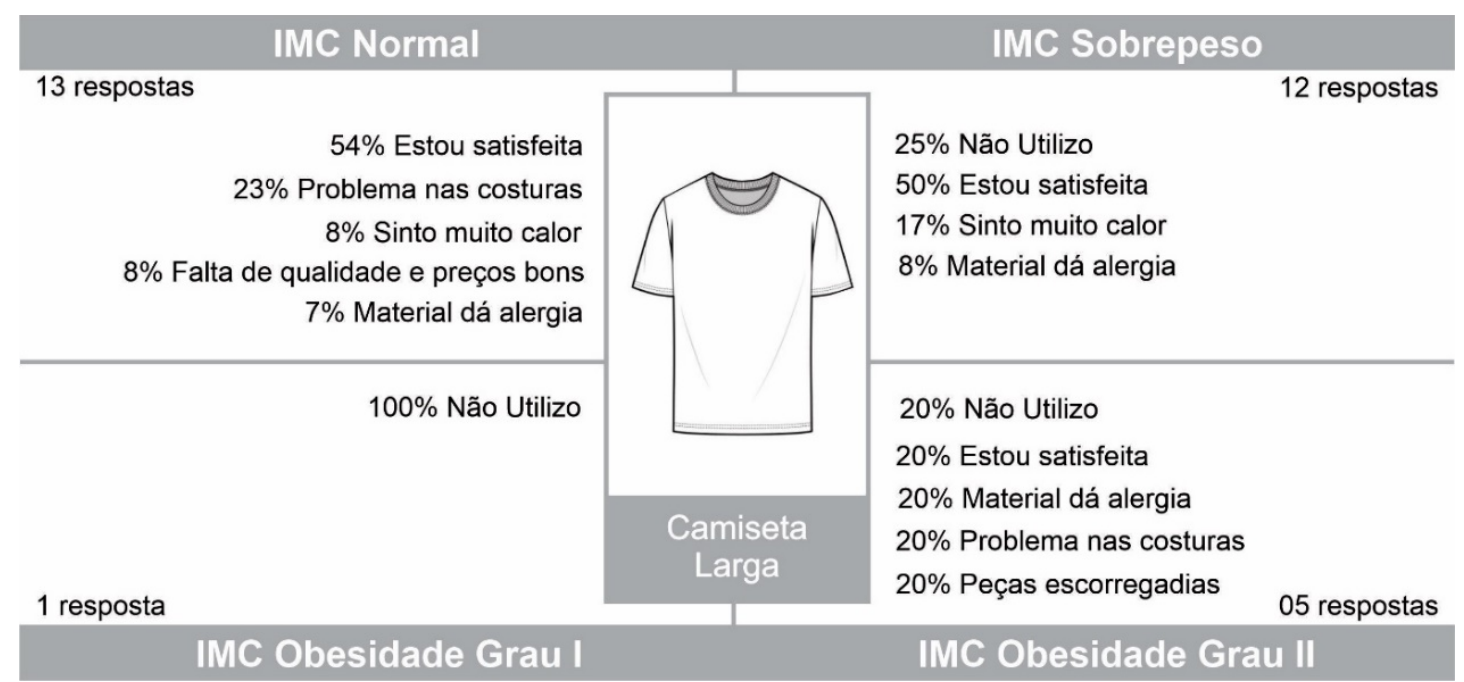

Figura 5: Avaliação da camiseta larga pelas participantes. Fonte: elaborado pelos autores (2020).

O quarto item avaliado foi a camiseta larga (Figura 5). Os principais problemas levantados pelo grande grupo foram: apresentam problema nas costuras (4 respostas), o material causa alergia (3 respostas), muito calor na utilização ( 3 respostas), faltam no mercado produtos com qualidade e preços bons (1 resposta), as peças são escorregadias (1 resposta).

O quinto item avaliado foi o macacão (Figura 6). Os principais problemas levantados pelo grande grupo foram: faltam no mercado produtos com qualidade e preços bons (7 respostas), sente muito calor na utilização (4 respostas), as peças são muito apertadas (3 respostas), não encontra do seu tamanho (3 respostas), o material causa alergia ( 2 respostas), as peças são escorregadias ( 2 respostas), apresentam problema nas costuras (1 resposta). 


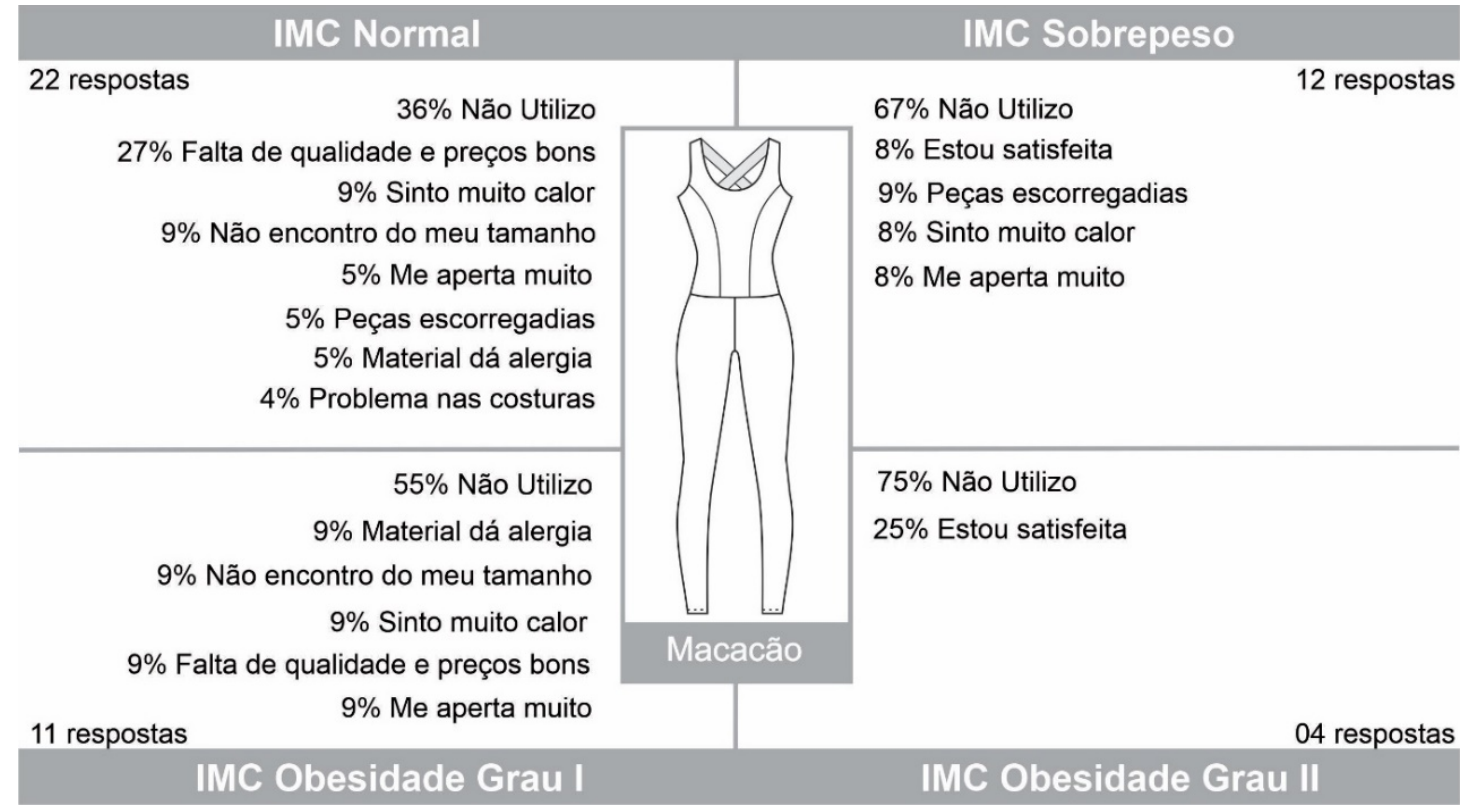

Figura 6: Avaliação do macacão pelas participantes. Fonte: elaborado pelos autores (2020).

Como uma síntese geral da avaliação das peças de vestuário para todos os perfis de IMC, ficaram respectivamente: faltam no mercado produtos com qualidade e preços bons (22 respostas), apresentam problema nas costuras (20 respostas), sente muito calor na utilização (14 respostas), o material causa alergia (13 respostas), as peças são muito apertadas (12 respostas), não encontra do seu tamanho (10 respostas), as peças são escorregadias ( 9 respostas). Não houve diferença significativa na avaliação dos produtos entre o grupo de IMC normal e os demais, pois apresentaram as mesmas queixas com relação aos produtos, como o tamanho, material, desconforto térmico e processos alergênicos, além da transparência das peças.

Com relação à avaliação feita pelas entrevistadas, à luz das as características de usabilidade de Iida (2016, p. 258), principalmente nos pontos de "alcance dos objetivos" e "uso amigável", ou seja, que contemplam a satisfação do usuário com eficiência e eficácia na realização da tarefa, bem como a "boa adaptação ergonômica (física e cognitiva), com conforto [...]", as peças apresentam diversos pontos que podem ser melhorados, tanto para as usuárias plus size quando para aquelas com o IMC normal. Algumas delas são: a melhoria do conforto térmico e hídrico dos materiais, bem como a inclusão de tecnologias antialérgicas e melhoria nas etapas de modelagem e costura - referentes à confecção -, já que, haja vista a natureza da atividade esportiva, são peças que recebem grande tensão nas costuras; a oferta destes produtos com bons preços; e a melhoria estética das peças, evidenciando um desejo por peças de qualidade, confortáveis, seguras e bonitas.

\section{Conclusão}

O presente trabalho buscou conhecer a percepção das usuárias plus size sobre o vestuário esportivo feminino, tendo como intenção verificar quais os principais problemas existentes nas peças utilizadas para, com isso, definir possíveis melhorias. Participaram da pesquisa 34 mulheres, sendo 12 delas com o IMC normal e 22 plus size - 11 com sobrepeso, 07 na faixa compreendida como obesidade grau I e 04 na faixa compreendida como obesidade grau II. Todas eram frequentadoras do programa "EmagreSer", ofertado no município de Caçador-SC. Optou-se pela participação das entrevistadas com IMC normal visando à construção de uma avaliação geral e comparativa entre os grupos. Um ponto relevante foi o engajamento das participantes com IMC Obesidade Grau I na prática esportiva, onde todas as sete mulheres praticam atividades físicas, buscando uma melhoria da saúde, enquanto os demais grupos apresentaram índices parciais de participação. 
Com relação à análise de vestuário, o ponto mais importante diz respeito aos principais requisitos para um bom vestuário esportivo, onde o grupo de maior IMC, Obesidade Grau II, citou apenas as características de conforto e qualidade, deixando para trás os demais tópicos apresentados, como estética e design, tecidos tecnológicos, durabilidade e preço. Já os demais grupos indicaram em quantidades expressivas todos os requisitos disponibilizados, o que demonstra que as mulheres com perfis corporais maiores têm real dificuldade de encontrar no mercado o mínimo que o vestuário esportivo precisa ter - conforto e qualidade. Os demais grupos, por terem as necessidades básicas do vestuário atendidas, acabaram citando mais itens como requisitos de escolha para esses produtos.

Dentre as sugestões de melhoria para os produtos, houve certa semelhança na avaliação dos mesmos nos grupos como um todo, onde as principais queixas foram: faltam no mercado produtos com qualidade $\mathrm{e}$ preços bons, problemas nas costuras, desconforto térmico, materiais que causam alergias, peças muito apertadas, grades de tamanho restritas e peças escorregadias.

As melhorias sugeridas podem ser aplicadas à confecção dos dois perfis de vestuário esportivo, tanto o plus size quanto o tradicional, principalmente no que se refere aos materiais utilizados. Os principais pontos de melhoria seriam: utilização de materiais que apresentem conforto térmico e hídrico; aprimoramento de modelagem e costuras reforçadas - por se tratar de peças que recebem grande tensão nas costuras pela natureza da atividade esportiva -; e a oferta destes produtos com bons preços.

Em especial para o vestuário esportivo plus size, são imprescindíveis adequações ergonômicas com relação ao material: tecidos que tenham maior conforto ao toque, como a poliamida (PA), maior conforto hídrico e adequação da escolha da gramatura com relação ao percentual de elasticidade, a fim de evitar transparências e estiramento demasiado da malha quando vestida. Também são importantes melhorias com relação à confecção, como costuras reforçadas e com bom acabamento, e à modelagem, como a adequação das peças para que essas realmente moldem-se a cada perfil de corpo, proporcionando conforto, segurança e, por conseguinte, auxiliando no engajamento da prática esportiva.

A semelhança nos resultados entre os grupos demonstra que não somente o vestuário esportivo plus size apresenta pontos a serem melhorados nos produtos, mas que o vestuário esportivo no geral pode desenvolver melhorias, pois foram relatadas muitas similaridades nas experiências negativas das usuárias com relação às peças apresentadas. Acredita-se que o vestuário esportivo é um nicho desafiador no que tange à adequação ao usuário, já que se tratam de peças que dão suporte a atividades muito dinâmicas e que se ajustam ao corpo, revelando todas as formas e contornos, o que muitas vezes é incômodo para as mulheres, conforme o estudo de Freitas (2010) demonstrou.

Como estudo futuro, seria pertinente o aprofundamento do perfil corporal e antropométrico das usuárias plus size, visando à construção de parâmetros que possam ser utilizados para a ampliação das grades tradicionais de tamanho pelas indústrias, com consequente melhoria no atendimento a esse público. Outro estudo recomendado diz respeito à avaliação de protótipos desenvolvidos a partir das observações levantadas nesta pesquisa, buscando validar as melhorias sugeridas e investigar novos pontos de aperfeiçoamento na confecção dessas peças.

\section{Referências Bibliográficas}

ASSOCIAÇÃO BRASILEIRA DE NORMAS TÉCNICAS. ABNT/CB-17 - Comitê Brasileiro de Têxteis e do Vestuário. Rio de Janeiro, 2014. ÂMBITO DE ATUAÇÃO: Normalização no campo da indústria têxtil e do vestuário. Disponível em: http://www.abnt.org.br/cb-17. Acesso em 21 fev. 2020.

BEST, Kathryn. Fundamentos de Gestão de Design. Porto Alegre: Bookman, 2012. 208 p. 
BETTI, Marcella Uceda. Beleza sem medidas? Corpo, gênero e consumo no mercado de moda plus-size. Dissertação (Mestrado em Antropologia Social). FFLCH-USP. São Paulo, 2014.

FONSECA-JUNIOR, Sidnei Jorge et al. Exercício físico e obesidade mórbida: uma revisão sistemática. :Abed - Arquivos Brasileiros de Cirurgia Digestiva, São Paulo, v. 1, n. 26, p. 67-73, jan. 2013. Trimestral. Disponível em: https://www.scielo.br/pdf/abcd/v26s1/a15v26s1.pdf. Acesso em: 20 fev. 2020.

FREITAS, Clara Maria Silveira Monteiro de et al. O padrão de beleza corporal sobre o corpo feminino mediante o IMC. Revista Brasileira de Educação Física e Esporte, [s.1.], v. 24, n. 3, p. 389-404, set. 2010. FapUNIFESP (SciELO). http://dx.doi.org/10.1590/s1807-55092010000300010.

GOMES FILHO, João. Design do Objeto: Bases Conceituais. São Paulo: Escrituras, 2006. , João. Ergonomia do Objeto: Sistema Técnico de Leitura Ergonômica. São Paulo: Escrituras, 2010.

IIDA, Itiro. Ergonomia: Projeto e Produção. 2. ed. São Paulo: Blucher, 2005.

JANNINK, Michiel et al. Questionnaire for usability evaluation of orthopaedic shoes: construction and reliability in patients with degenerative disorders of the foot. Journal Of Rehabilitation Medicine, [s.1.], v. 36, n. 6, p.242-248, 1 nov. 2004. Acta Dermato-Venereologica. http://dx.doi.org/10.1080/16501970410033569.

KOUPRIE, Merlijn; VISSER, Froukje Sleeswijk. A framework for empathy in design: stepping into and out of the user's life. Journal Of Engineering Design, [s.1.], v. 20, n. 5, p.437-448, out. 2009. Informa UK Limited. http://dx.doi.org/10.1080/09544820902875033.

KOZLOWSKI, Anika; BARDECKI, Michal; SEARCY, Cory. Tools for Sustainable Fashion Design: An Analysis of Their Fitness for Purpose. Mdpi: Sustainability, Toronto, v. 3581, n. 11, p.1-19, jun. 2019. Disponível em: <https://www.mdpi.com/2071-1050/11/13/3581>. Acesso em: 18 fev. 2020.

LIMA, Anizielle Aparecida de; MAFFIA, Roseny Maria. Motivos de adesão à prática de atividades físicas em academias femininas. Lecturas: Educación Física y Deportes, Buenos Aires, v. 143, n. 15, p. 1-14, abr. 2010. Disponível em: https://www.efdeportes.com/efd143/adesao-a-pratica-em-academias-femininas.htm. Acesso em: 20 fev. 2020.

LIMATIUS, Hanna. "I'm a fat bird and I just don't care": A corpus-based analysis of body descriptors in plus-size fashion blogs. Discourse, Context \& Media, [s.1.], v. 31, p.1-11, out. 2019. Elsevier BV. http://dx.doi.org/10.1016/j.dcm.2019.100316.

MERINO, Giselle Schmidt Alves Díaz. METOdOlOGIA PARA A PRÁTICA PROJETUAL DO DESIGN: com base no Projeto Centrado no Usuário e com ênfase no Design Universal. 2014. 242 f. Tese (Doutorado) - Curso de Engenharia de Produção, Universidade Federal de Santa Catarina, Florianópolis, 2014. Disponível em: $<$ https://repositorio.ufsc.br/xmlui/handle/123456789/128821>. Acesso em: 15 fev. 2020.

MONTEMEZZO, Maria Celeste. Diretrizes metodológicas para o projeto de produtos de moda no âmbito acadêmico. Bauru, 2003. Dissertação (Mestrado) - UNESP, Universidade Estadual Paulista, Faculdade de Arquitetura, Artes e Comunicação.

MOORHOUSE, Debbie; MOORHOUSE, Danielle. Sustainable Design: circular economy in fashion and textiles. : Circular Economy in Fashion and Textiles. The Design Journal, [s.1.], v. 20, n. 1, p. 1948-1959, 
28 jul. 2017. Informa UK Limited. http://dx.doi.org/10.1080/14606925.2017.1352713. Disponível em: https://www.tandfonline.com/doi/pdf/10.1080/14606925.2017.1352713?needAccess=true. Acesso em: 20 fev. 2020.

NASCIMENTO, Jaqueline Lovato do. $\mathbf{O}$ vestuário fitness para mulheres com sobrepeso como motivador à prática de exercícios físicos. 2014. 144 f. TCC (Graduação) - Curso de Design de Moda, Universidade Tecnológica Federal do Paraná, Apucarana, 2014.

PRODANOV, Cleber Cristiano; FREITAS, Ernani Cesar de. Metodologia do trabalho científico: métodos e técnicas da pesquisa e do trabalho acadêmico. 2. ed. Novo Hamburgo: Feevale, 2013. 277 p. Disponível em: http://www.feevale.br/Comum/midias/8807f05a-14d0-4d5b-b1ad-1538f3aef538/Ebook\%20Metodologia\%20do\%20Trabalho\%20Cientifico.pdf. Acesso em: 20 fev. 2020.

ROSA, Lucas da. Vestuário industrializado: uso da ergonomia nas fases de gerência de produto, criação, modelagem e prototipagem.2011. 176 f. Tese (Doutorado) -Curso de Design, Pontifícia Universidade Católica do Rio de Janeiro, Rio de Janeiro, 2011. Cap. 11. Disponível em: $<$ http://www.maxwell.vrac.puc-rio.br/18873/18873_1.PDF>. Acesso em: 21 out. 2020.

ROSA, Maria Inês da et al. Prevalência e fatores associados à obesidade em mulheres usuárias de serviços de pronto-atendimento do Sistema Único de Saúde no sul do Brasil. Ciência \& Saúde Coletiva, Rio de Janeiro, v. 5, n. 16, p.2559-2566, jul. 2011.

SANTOS, Ana Pessoa; NICOLAU, Ayalla Simone. Moda para além da medida - o Plus Size no mercado fashion: de uma visão Frankfurtiana a perspectiva dos Estudos Culturais. In: XVII Congresso de Ciências da Comunicação na Região Sudeste, Ouro Preto, MG, 2012. Disponível em:

$<$ http://www.intercom.org.br/papers/regionais/sudeste2012/resumos/R33-0699-2.pdf $>$. Acesso em 15 fev. 2020

SANTOS, Sabrina Pereira dos. Processo de busca de consumidoras de moda-vestuário plus size: do corpo à roupa que veste o corpo. 2016. $121 \mathrm{f}$. Dissertação (Mestrado) - Curso de Consumo, Cotidiano e Desenvolvimento Social, Ciência Doméstica, Universidade Federal Rural de Pernambuco, Recife, 2016. Disponível em:

$<$ http://www.tede2.ufrpe.br:8080/tede2/bitstream/tede2/7534/2/Sabrina\%20Pereira\%20dos\%20Santos.pdf $>$. Acesso em: 01 dez. 2019.

SAÚDE, Ministério da. Brasileiros atingem maior índice de obesidade nos últimos treze anos. 2019. Por: Alexandre Penido. Disponível em: $<$ https://www.saude.gov.br/noticias/agencia-saude/45612-brasileirosatingem-maior-indice-de-obesidade-nos-ultimos-treze-anos>. Acesso em: 12 fev. 2020.

SCHULTE, Neide Köhler. Reflexões sobre moda ética: contribuições do biocentrismo e do veganismo. Florianópolis: Editora da Udesc, 2015. 160 p.

SILVA, Natália Magalhães. O CONSUMIDOR PLUS SIZE COMO UM NOVO PADRÃO ESTÉTICO NA MODA CONTEMPORÃNEA. 2012. 62 f. Monografia (Especialização) - Curso de Especialização em Estética e Gestão de Moda São Paulo, Escola de Comunicação e Artes, Universidade de São Paulo, São Paulo, 2012. Disponível em: http://www2.eca.usp.br/moda/monografias/Natalia\%20Magalhaes.pdf. Acesso em: 15 fev. 2020.

SOUZA, Michelle et al. O futuro da obesidade no Brasil: uma previsão a partir do Método Lee-Carter (20062030). In: XXI ENCONTRO DE ESTUDOS POPULACIONAIS, 20., 2019, São Bernardo do Campo. Anais... . São Bernardo do Campo: Abep, 2019. p. 01 - 04. Disponível em: $<$ http://www.abep.org.br/publicacoes/index.php/anais/article/view/3036>. Acesso em: 15 fev. 2020. 
TAVARES, Telma Braga; NUNES, Simone Machado; SANTOS, Mariana de Oliveira. Obesidade e qualidade de vida: revisão da literatura. Revista Médica de Minas Gerais, Belo Horizonte, v. 3, n. 20, p.359-366, out. 2010. Disponível em: <http://rmmg.org/artigo/detalhes/371>. Acesso em: 12 fev. 2020.

WANDERLEY, Emanuela Nogueira; FERREIRA, Vanessa Alves. Obesidade: uma perspectiva plural.: Ciência \& Saúde Coletiva, Rio de Janeiro, v. 1, n. 15, p. 185-194, abr. 2010. Disponível em: https://www.scielosp.org/pdf/csc/2010.v15n1/185-194/pt. Acesso em: 20 fev. 2020.

Deverão estar ao final do texto do artigo, considerando número total de páginas. As Referências Bibliográficas deverão estar citadas segundo as normas da ABNT, conforme exemplos abaixo:

\section{Agradecimentos}

À nutricionista Karine Venâncio do programa “EmagreSer”, pela parceria na pesquisa.

À Matheus Baldez Reis, pela revisão e contribuições no texto. 